\title{
Case study scenarios in site selection of hazardous material facilities based on transportation preferences
}

\author{
Babak Mehran ${ }^{1}$ (I) Musharraf Ahmad Khan ${ }^{1} \cdot$ Mina Mehran $^{2} \cdot$ \\ Hyukjae Roh $^{3}$ - Satish Sharma ${ }^{2}$
}

Received: 19 February 2019/Revised: 2 May 2019/Accepted: 17 May 2019/Published online: 8 June 2019

(C) The Author(s) 2019

\begin{abstract}
A methodology is proposed to evaluate and rank potential sites for facilities dealing with hazardous materials (HAZMAT). The proposed methodology incorporates HAZMAT route planning into facility siting while considering transportation preferences and challenges. The area of interest is divided into smaller zones representing potential sites for a HAZMAT facility. A multimodal transportation network including railways and roads is considered for transportation of HAZMAT. Each zone is evaluated based on its accessibility from a set of selected points of interests (POIs), which are defined as potential origin/destination points for transportation of HAZMAT. The shortest routes between each POI and potential zones are evaluated based on a cost function which can accommodate multiple criteria to determine the associated disutility for each potential zone. Finally, zones are ranked based on their cumulative disutility scores. The proposed
\end{abstract}

Babak Mehran

babak.mehran@umanitoba.ca

Musharraf Ahmad Khan

khanma2@myumanitoba.ca

Mina Mehran

mehran2m@uregina.ca

Hyukjae Roh

roh204@uregina.ca

Satish Sharma

satish.sharma@uregina.ca

1 Department of Civil Engineering, University of Manitoba, 66 Chancellors Cir, Winnipeg, MB R3T 2N2, Canada

2 Faculty of Engineering and Applied Science, University of Regina, 3737 Wascana Pkwy, Regina, SK S4S 0A2, Canada

3 City of Regina, 2476 Victoria Avenue, Regina, SK S4P 3C8, Canada analysis method is quantitative, and at the same time it is adequately flexible to allow inclusion of subjective criteria. Application of the proposed methodology is demonstrated for identifying optimal locations for a HAZMAT facility (e.g., a nuclear facility) using the Canadian province of Saskatchewan as an example. Three scenarios were evaluated including (1) all network segments and POIs were treated equally, (2) network segments were rank ordered based on their functional classification while POIs were treated equally and (3) network segments were rank ordered based on their functional classification with preferences given to specific POI(s).

Keywords HAZMAT transportation - Site selection . Route planning $\cdot$ Shortest path analysis

\section{Introduction}

Siting of facilities handling hazardous materials (HAZMAT) is a multidisciplinary process aiming to satisfy the needs and interests of different stakeholders including the general public and political, health, transportation, and environmental authorities. Examples of HAZMAT facilities include nuclear power plants, medical and research facilities using nuclear materials, chemical plants, and refineries. The siting process is often considered as a multiobjective optimization problem as stakeholders may have different and even contradicting needs and interests. Transportation challenges and preferences are among the main determining factors in HAZMAT facility siting process. Availability of an efficient transportation network is essential for seamless and safe transportation of (1) construction materials, (2) mechanical parts and machinery, 
and (3) HAZMAT materials, as well as providing access to emergency response services in the case of an accident.

Depending on the type of HAZMAT facility, transportation of hazardous materials may take place periodically between specific locations and the facility as long as it is in operation. For example, in the case of a nuclear fuel fabrication facility, the raw materials are transported from supply locations (e.g., a uranium mine) to the facility site, and the fabricated fuel is transported from the facility site to where it is needed (e.g., nuclear power plants and research reactors). While one end of transportation route is often the HAZMAT facility site, the other end can be in different locations such as another city, province or even country. Thus, often there is a set of specific 'points of interest' (POIs) which should be accessible from and connected to the HAZMAT facility through ground transportation network. Examples of such POIs are nearby urban centers, intermodal freight terminals, and highway locations at interprovincial and international borders. Therefore, route planning has a significant impact on site selection for HAZMAT facilities.

Transportation of HAZMAT is strictly regulated through local and national codes such as Transportation of Dangerous Goods Regulations [1] under Transportation of Dangerous Goods Act 1992 [2], and international codes and regulating bodies such as International Atomic Energy Agency (IAEA) [3] in the case of nuclear materials. One of the initial necessary steps in HAZMAT route planning is transportation risk assessment, which is essential for mitigating the impact of any potential transportation-related incidents. HAZMAT transportation route should be capable of accommodating specific weights and dimensions (e.g., freight and vehicle), with minimum congestion levels, good road safety records, and preferably away from sensitive areas such as population centers, water bodies, and parks. Thus, HAZMAT route planning provides an opportunity to minimize the time that the public and environment can be potentially exposed to hazardous materials (i.e., exposure).

In this paper, a siting analysis method is proposed to identify and rank potential zones for any HAZMAT facility by identifying the routes with minimum disutility between predefined POIs and potential zones in terms of accessibility, preference, and suitability of the routes in a multimodal network including roadways and railways. The unique feature of the proposed methodology is that it incorporates route planning into HAZMAT facility site selection process. After a brief literature review, the proposed methodology is described. Next, several case studies are presented to demonstrate the application of the methodology for identifying optimal locations for a HAZMAT facility (e.g., a nuclear facility) using the Canadian province of Saskatchewan as an example, which is followed by a discussion on analysis results. The last section provides the conclusions and potential directions for future research.

\section{Literature review}

There are various approaches and selection criteria for HAZMAT route planning. The common point of all these approaches is the trade-off between safety and the cost of HAZMAT transportation. As public safety is interpreted in different ways, agencies have defined particular measures to maintain public safety. Such trade-offs have resulted in a variety of HAZMAT transportation route selection methods to retain safety needs [4].

A common method for identifying the best routes for transportation of HAZMAT is through surveys, which is qualitative and subjective. In this method [5], a multidisciplinary committee is formed to review and identify the suitable routes based on each committee members' priorities and expertise. Various factors such as traffic volumes, collision rate, roadway classification, adjacent land uses, and the type of HAZMAT may be considered. Another approach for HAZMAT route planning is the so-called D numbers method which was proposed to address the fuzziness and uncertainties included in route selection process $[6,7]$. In D numbers method, three main criteria are considered, i.e., the cost of transportation, risks of transportation, and emergency response. Each road segment is scored based on the combination of these criteria, and the best routes for shipping HAZMAT are found by identifying the routes with better scores. Some works (e.g., $[8,9])$ have used multi-objective optimization in HAZMAT route planning. In this approach, mathematical techniques are used to solve multi-objective optimization equations which result in identifying the best route based on a set of objectives. Ma [10] applied a multi-objective genetic algorithm (GA) to find optimal HAZMAT transportation routes under uncertain risk and travel time. In another study, Ma et al. [11] proposed a route screening model to find Pareto optimal HAZMAT transportation routes considering stochastic transportation risks and travel times by applying a GA and neural network (NN)-based multi-objective optimization algorithm. Other studies [12] suggested the use of 'catastrophe avoidance models' for HAZMAT route planning which focus on the worst-case scenarios and possible adverse effects on the public and environment in the event of an accident. Rocchi et al. [13] used a combination of different criteria and weight factors to identify the best HAZMAT transportation route. Weight factors for each criterion indicate the risk levels and the difficulty in controlling the risk posed by each criterion. 
Potential transportation routes are ranked based on their risk score to identify the best route.

Another important aspect in this research is optimization of site selection process. Geographic information system (GIS)-based spatial data analysis methods have been used to find the optimal locations for emergency response services $[14,15]$ and solid waste landfills [16]. Kazemi et al. [17] used GIS to determine optimal fire station locations based on travel times. Other site selection approaches for fire station services include the use of analytical hierarchy process and multicriteria decision making [18], and optimization algorithms such as ant colony optimization, GA, and fuzzy multi-objective analysis $[19,20]$. The focus of the majority of existing research in this area is on facilities such as emergency response services and fire stations. Only a few studies attempted to address HAZMAT facility siting. Some examples include the use of map algebra for siting nuclear waste facilities [21], and application of GISbased multicriteria decision analysis for evaluating new power-generating sites [22] and site selection for hazardous waste landfills [23].

In this research, a quantitative method is proposed to identify and evaluate the best route for transportation of HAZMAT, based on which, the potential sites for any HAZMAT facility can be ranked with respect to their associated disutility by incrementally applying different criteria in the process. The proposed method is straightforward and flexible in the sense that it can accommodate various criteria into site selection process and it allows preferential treatment of specific sites, POIs, and route attributes.

\section{Methodology}

The analysis method proposed in this research applies a cost minimization algorithm (e.g., the shortest path algorithm) to find optimal transportation routes between POIs and potential zones for the HAZMAT facility. It is hypothesized that minimizing the cost function across transportation routes will result in minimum exposure to associated risks for the public and environment in case of possible incidents. In this context, the cost function represents the disutility of a route used for transportation of HAZMAT. The analysis steps are presented in Fig. 1.

\subsection{Step 1: identification of network elements}

The area of interest for a HAZMAT facility is divided into a network of smaller zones. Various zoning schemes such as rectangular zones with different dimensions can be adopted depending on the project scope and preferences.

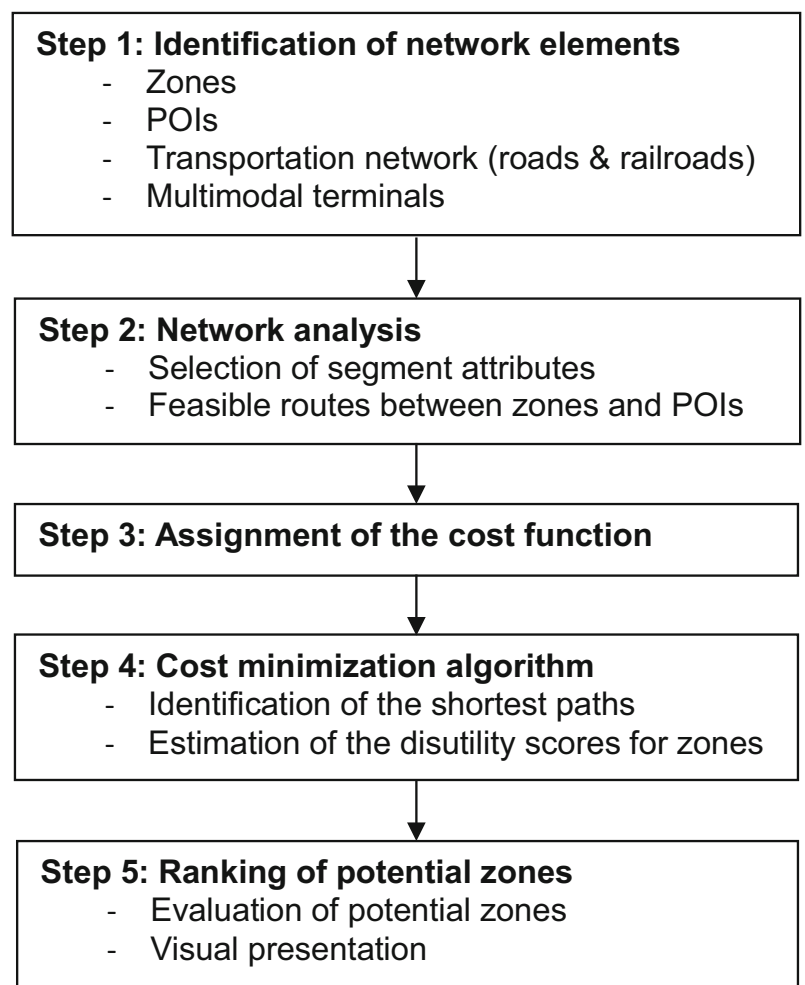

Fig. 1 Analysis steps for evaluating potential zones for a HAZMAT facility

Each zone is represented by its geographical centroid. Infeasible or sensitive areas such as water bodies and parks can be excluded from the analysis. A desired buffer distance can be defined to exclude sensitive and infeasible areas, respectively. As discussed earlier, POIs are defined as important points which should be accessible from and connected to the facility site. A desired number of POIs are defined based on the project's practical needs and short-, medium-, and long-term planning objectives. In this research, a multimodal transportation network including railways and roads is considered for transportation of HAZMAT. Transfer between road and railway network is feasible only at multimodal freight terminals. In this paper, 'network' refers to the combined network of roads and railways including multimodal freight terminals while 'segment' encompasses both road and railway segments unless mentioned otherwise. To evaluate the connectivity between POIs and potential zones, a digital map of the area of interest is required which contains detailed information of roads and railway segments, and multimodal freight terminals. The network analysis tasks in the proposed method can be handled using any GIS data analysis tool capable of performing network and spatial analysis including shortest path analysis. 


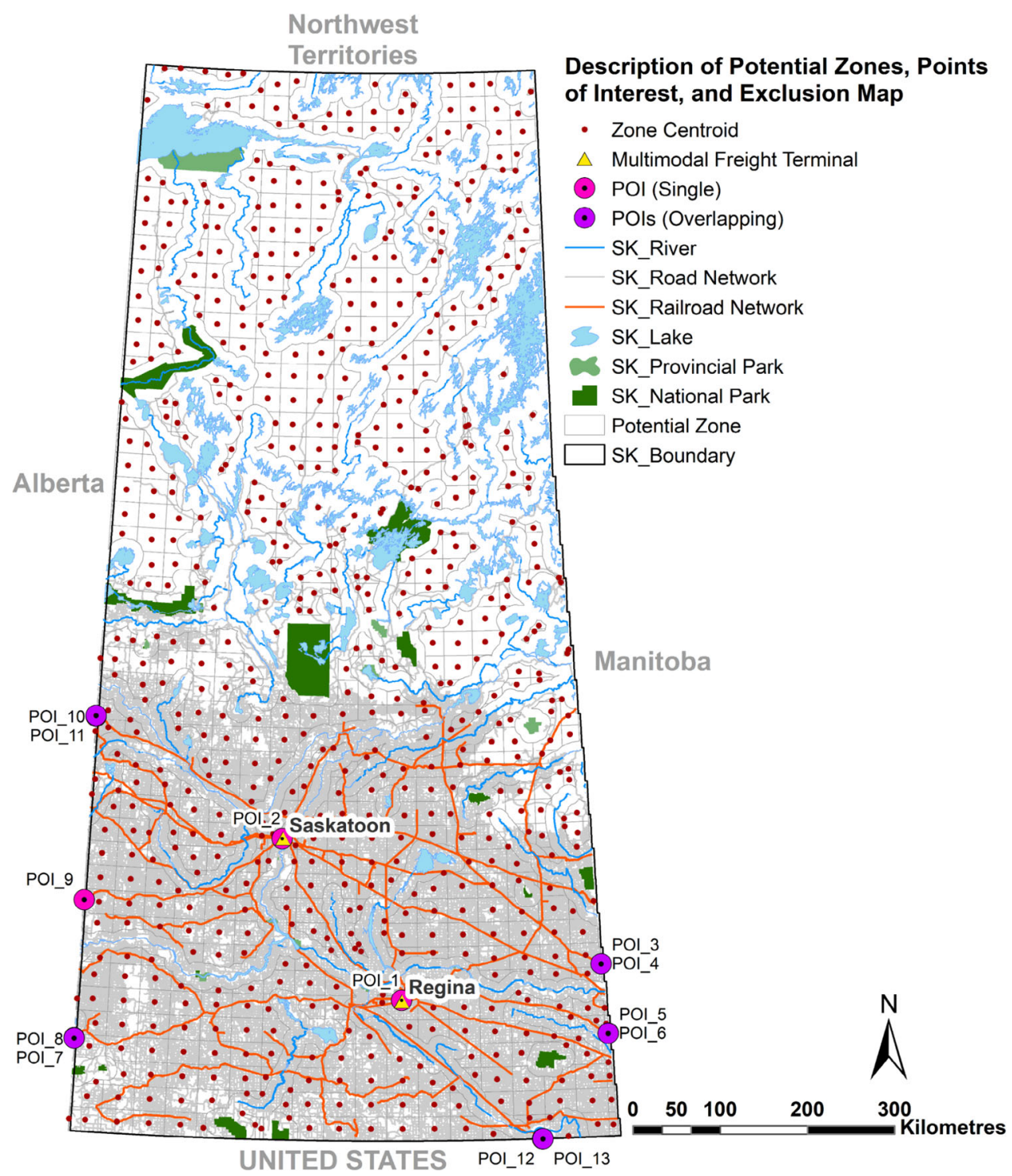

Fig. 2 Road network, potential zones, points of interest, and exclusion areas

\subsection{Step 2: network analysis}

Different types of criteria can be considered in route selection process when planning for transportation of HAZMAT. For example, highway segments may be preferred over arterial roads as they are less congested and with much less number of intersections. Likewise, road segments away from population centers and sensitive areas may be preferred. Similarly, railroads may be preferred over highways due to better safety records and additional load-bearing capacity. Required attributes should be assigned to each road and railway segment in the network. Examples of such attributes include road and railroad category, road surface conditions, length, geometry, load- bearing capacity, lateral and vertical clearances, distance from population centers, proximity to emergency response services, connectivity to multimodal terminals, etc. Consequently, a spatial analysis should be conducted to determine all feasible routes between POIs and potential zones in the network. Identified feasible routes must be recorded for further analysis.

\subsection{Step 3: assignment of the cost function}

The cost function combines all route selection criteria and weight factors, which represent the significance of each criterion. The cost function is the most important feature assigned to the segments in the network. Each feasible 


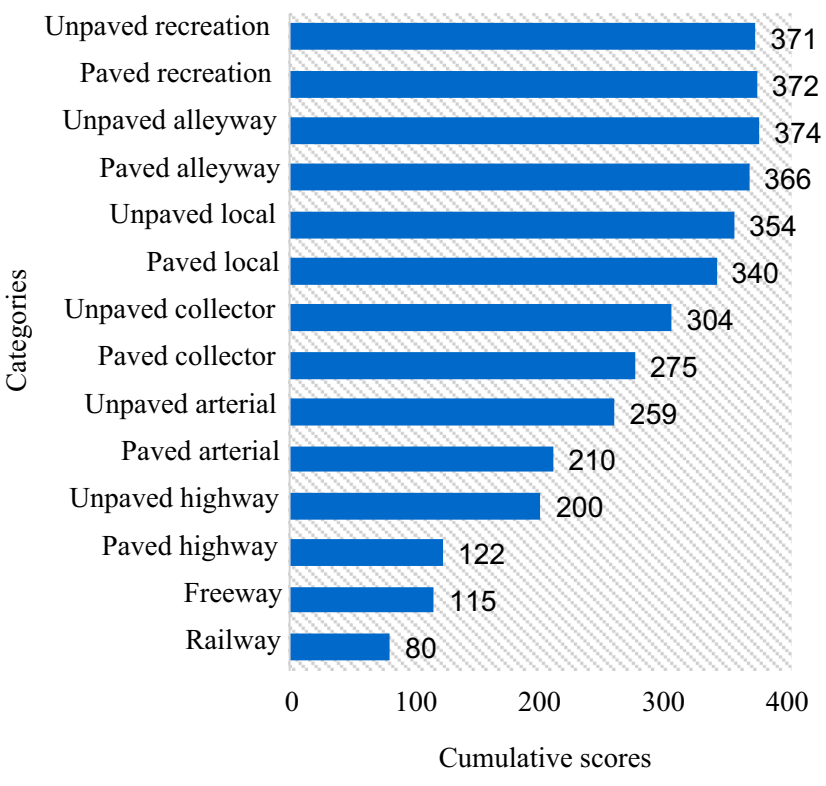

(a) Cumulative scores surveyed from experts for each category (least is most preferrable)

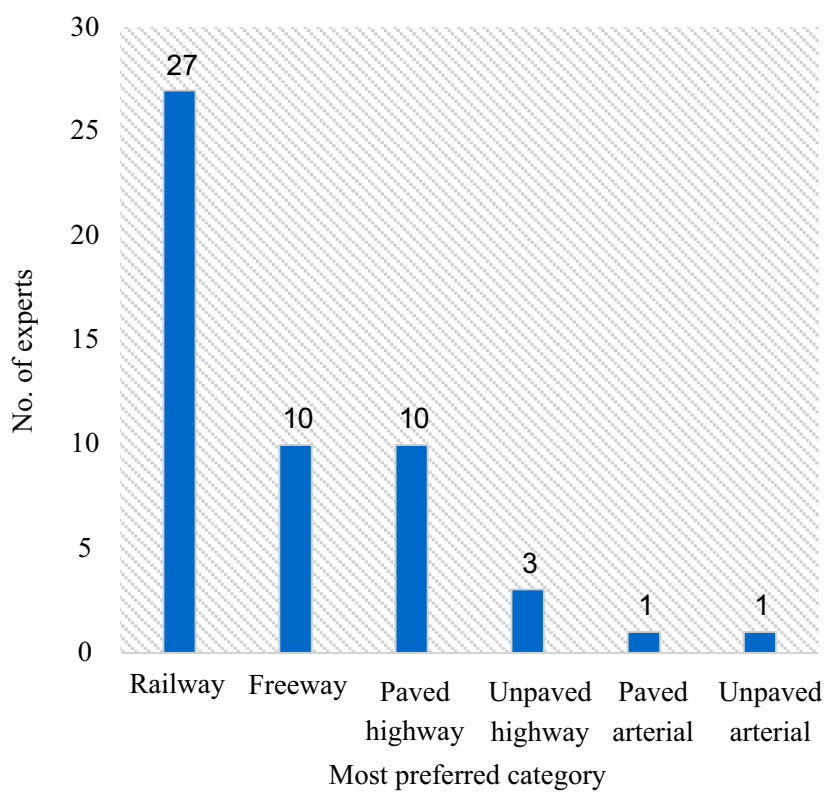

(b) Preferred means of transportation with rank score of ' 1 '

Fig. 3 Preference scores and the most preferred means of transportation for nuclear materials

route consists of many smaller segments with different features. All feasible routes are evaluated based on their corresponding segments' cost function values. Equation (1) presents a linear cost function $\left(c_{s}\right)$ for segment $s$ considering $n$ attributes $\left(f_{j}\right)$ for the segment. The significance of each attribute is presented by a desired weight factor $\left(\alpha_{j}\right)$ :

$c_{s}=\sum_{j=1}^{n} \alpha_{j} f_{j}$.

Different functional forms can be considered to combine multiple criteria depending on project goals and priorities. Weight factors are determined based on the significance of each road segment attribute in route selection analysis and can be estimated based on field observations or through surveys and questionnaires seeking experts' opinion.

\subsection{Step 4: cost minimization algorithm}

For each zone, the shortest path algorithm is used to evaluate all feasible routes between the zone's centroid and each POI based on the value of the cost function assigned to the segments of the routes. For zone $i$ and $\mathrm{POI}_{j}$, the cost along the shortest path $\left(\mathrm{SP}_{i j}\right)$ consisting of $q$ segments is estimated by summing the values of the cost function assigned to each segment $\left(c_{s}\right)$ using Eq. (2):

$\mathrm{SP}_{i j}=\sum_{s=1}^{q} c_{s}$

As presented in Eq. (3), given $m$ as the number of POIs, the disutility score for zone $i\left(\mathrm{DUS}_{i}\right)$ is calculated as the sum of the costs along the shortest paths $\left(\mathrm{SP}_{i j}\right)$ from all POIs to zone $i$ 's centroid. Logarithmic transformation was applied to smoothen the variations of DUS values across the zones:

$\operatorname{DUS}_{i}=\log \left(\sum_{j=1}^{m} \mathrm{SP}_{i j}\right)$.

Table 1 Cost function parameters used for Case I and Case II analyses

\begin{tabular}{|c|c|c|c|}
\hline Parameter & $n$ & $\alpha_{j}$ & $f_{j}$ \\
\hline Case I values & 1 & 1 & Segment length $(\mathrm{km})$ \\
\hline Case II values & 1 & $\begin{array}{l}\text { Determined for railways, and each road } \\
\text { category and surface type through } \\
\text { a survey from field experts (see Table } 2 \text { ) }\end{array}$ & Segment length $(\mathrm{km})$ \\
\hline
\end{tabular}




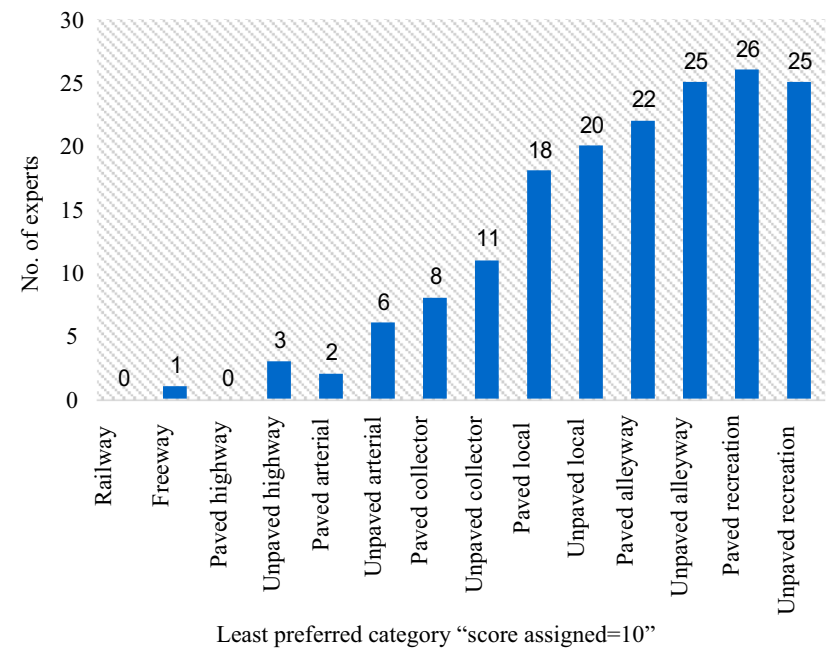

Fig. 4 Least preferred means of transportation for nuclear materials with rank score of ' 10 '

\subsection{Step 5: ranking of potential zones}

The disutility scores estimated in the previous step are assigned to each zone. To make the disutility scores comparable within a similar scale, a normalization process is proposed as in Eq. (4) to estimate the adjusted disutility score $\left(\mathrm{ADUS}_{i}\right)$ for each zone, which is a number between 0 and 100:

$\mathrm{ADUS}_{i}=\frac{\mathrm{DUS}_{i}-\min \left\{\mathrm{DUS}_{i}\right\}}{\max \left\{\mathrm{DUS}_{i}\right\}-\min \left\{\mathrm{DUS}_{i}\right\}} \times 100$.

In Eq. (4), $\min \left\{\mathrm{DUS}_{i}\right\}$ and $\max \left\{\mathrm{DUS}_{i}\right\}$ refer to the lowest and the highest disutility scores estimated across all zones, respectively. Adjusted disutility scores are assigned to each zone and used as the basis for evaluating the suitability of zones as potential site for the HAZMAT facility. Appropriate color-coding scheme is adopted to visually represent each potential zone based on its adjusted disutility score. The final results can be presented using heat maps.

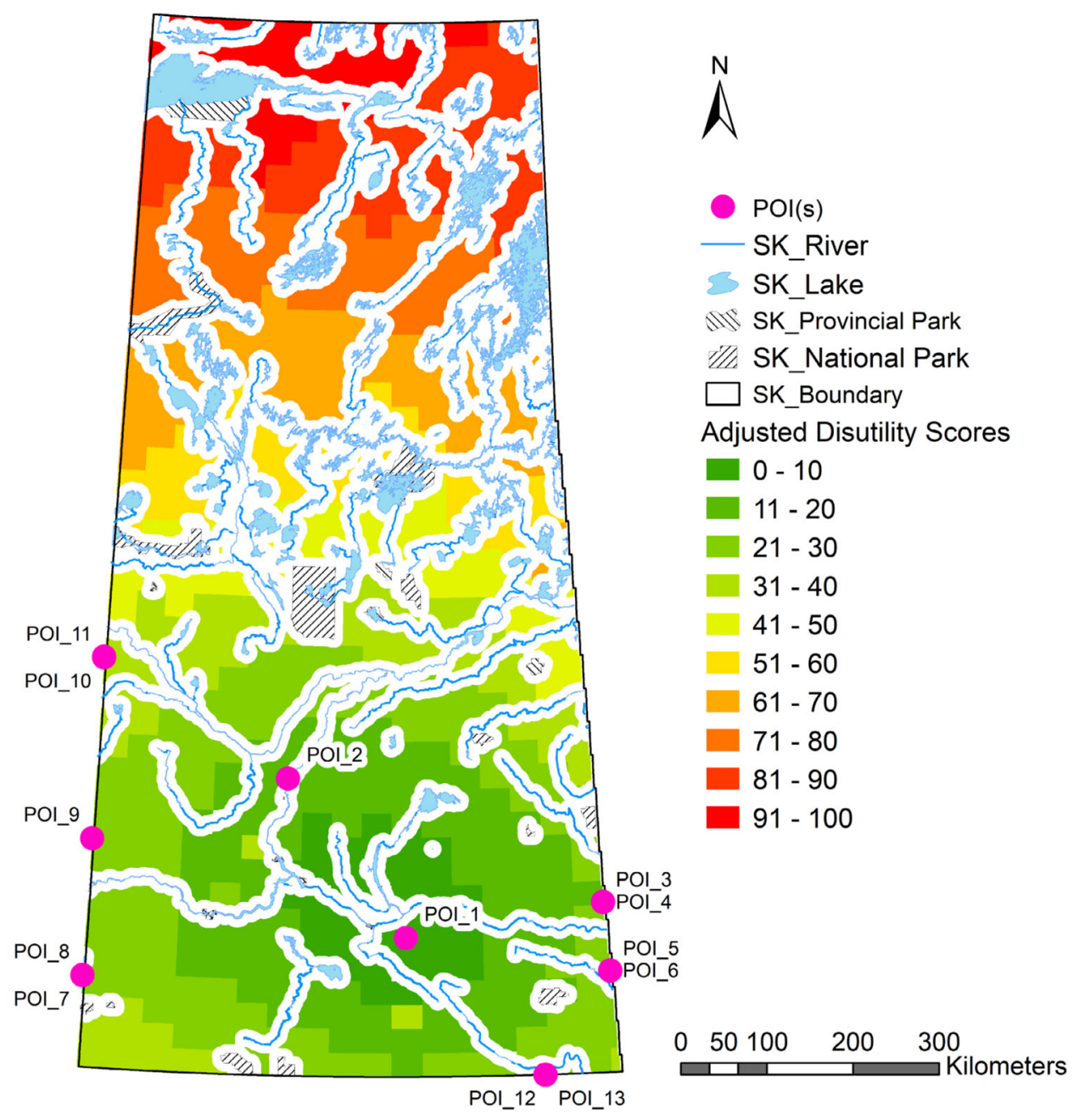

Fig. 5 Case I heat map 


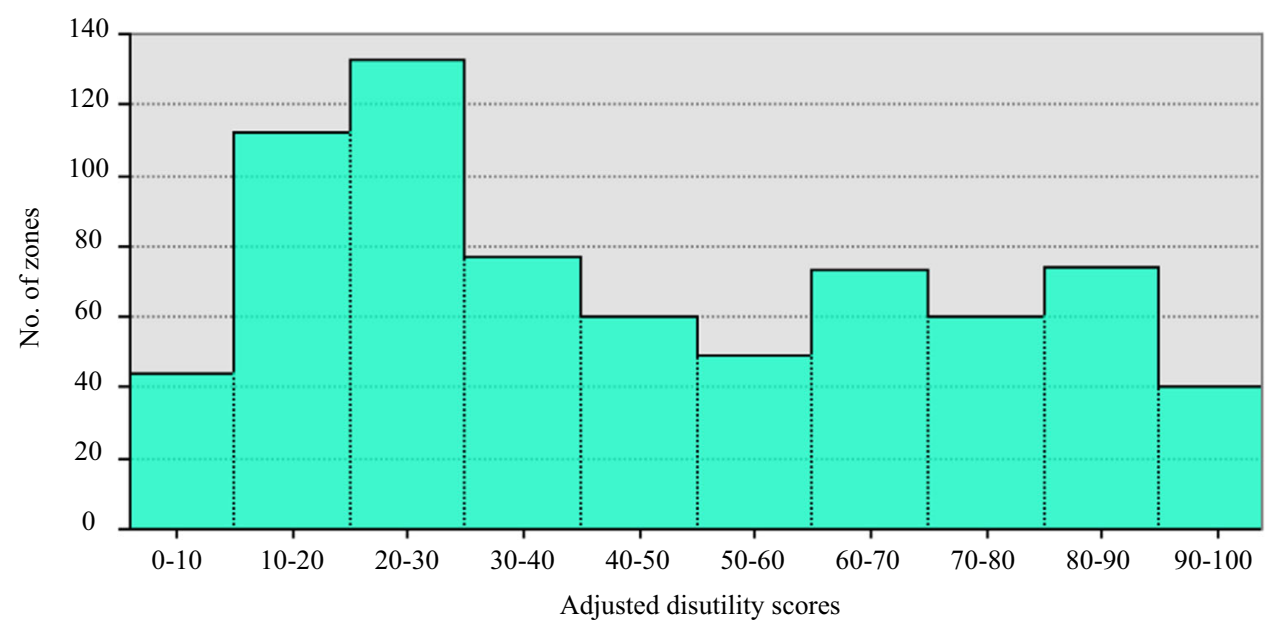

Fig. 6 Case I histogram for ADUS

\section{Application of the proposed analysis method}

The proposed analysis method was applied to identify the optimal sites for a HAZMAT facility (e.g., a nuclear facility) in the Canadian province of Saskatchewan.

As shown in Fig. 2, the National Topographic Mapping System (NTS) [24] which provides an efficient grid system based on longitudes and latitudes was adopted to divide the map of Saskatchewan into potential zones where each zone represents a candidate site for the facility. In total, 722 zones were identified. Each zone is represented by its centroid which is identified on the map. It should be noted that many zones may be infeasible as a HAZAMAT facility site because of their proximity to environmentally sensitive areas such as parks and water bodies and therefore were eliminated from the analysis. An exclusions layer was overlaid on NTS layer to mark and exclude infeasible zones. A buffer distance of $10 \mathrm{~km}$ was considered around infeasible areas to expand exclusion areas.

For demonstration purpose, 13 locations were identified in Saskatchewan as POIs. POIs 1 and 2 were identified in the cities of Regina and Saskatoon representing multimodal freight terminals, which indicate feasible HAZMAT transfer points between roads and railways. Considered multimodal terminals include the Canadian National Railway (CNR) freight terminal in Saskatoon and the freight terminal at Global Transportation Hub (GTH) in Regina. POIs 3 through 11 were considered along interprovincial highways and railways at Manitoba (Highways 1, Highway 16 , and adjacent railroads along both highways) and Alberta borders (Highway 1, Highway 7, Highway 16, and adjacent railroads along Highway 1 and Highway 16). Finally, POIs 12 and 13 were considered at the US border along Highway 39 (border crossing point) and at the adjacent railway border crossing point along Highway 39, respectively. Due to close proximity of POIs on railways and adjacent highway locations, it was not possible to show such POIs individually. Thus, overlapping POIs are indicated with additional labels in Fig. 2. Identified POIs were considered as potential start/end points for trips (truck or train) that carry HAZMAT to/from potential zones in Saskatchewan, which are considered for the HAZMAT facility site.

The National Road Network (NRN) [25] and National Railway Network (NRWN) [26] spatial data for the province of Saskatchewan were used as the basic datasets for network analysis. It is assumed that NRWN and multimodal freight terminals are available for HAZMAT transportation, irrespective of their ownership, operational or legal status. The NRN layer contains detailed data for the road segments such as road length, functional classification, surface type, and other important information. The NRWN contains detailed information on railroads such as operational tracks and categories in terms of freight or passenger.

Three case studies are presented to demonstrate the applications of the proposed analysis method: (1) Case I: all segments (i.e., road and railway segments) and POIs are treated equally, (2) Case II: segments are rank ordered based on their functional categories while POIs are treated equally, and (3) Case III: segments are rank ordered based on their functional categories with preferences given to specific POI(s).

\subsection{Case I}

The first case study represents a single-criterion analysis based on the segments' length only. Equation (1) was used to estimate the value of the cost function for each segment 


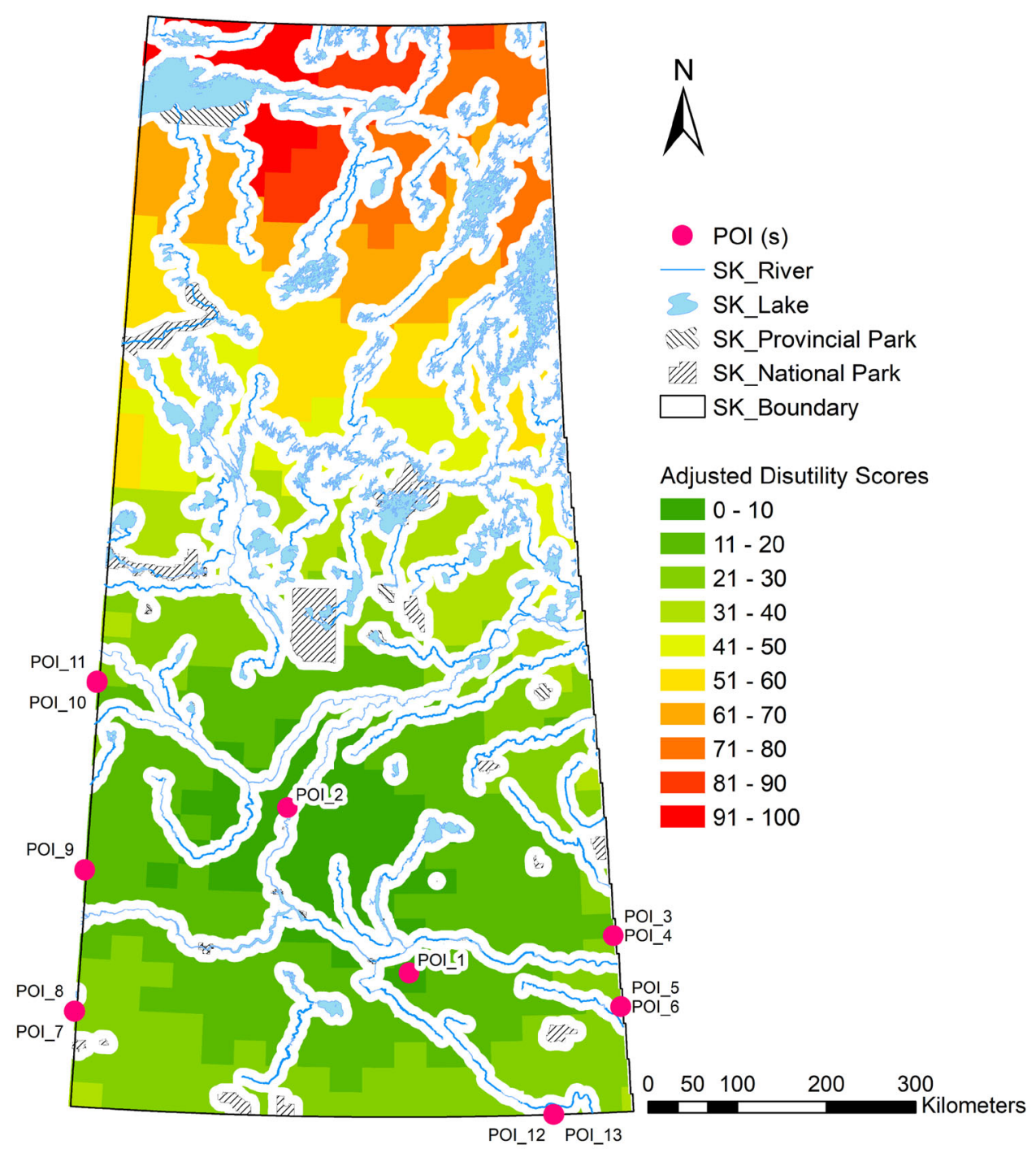

Fig. 7 Case II heat map

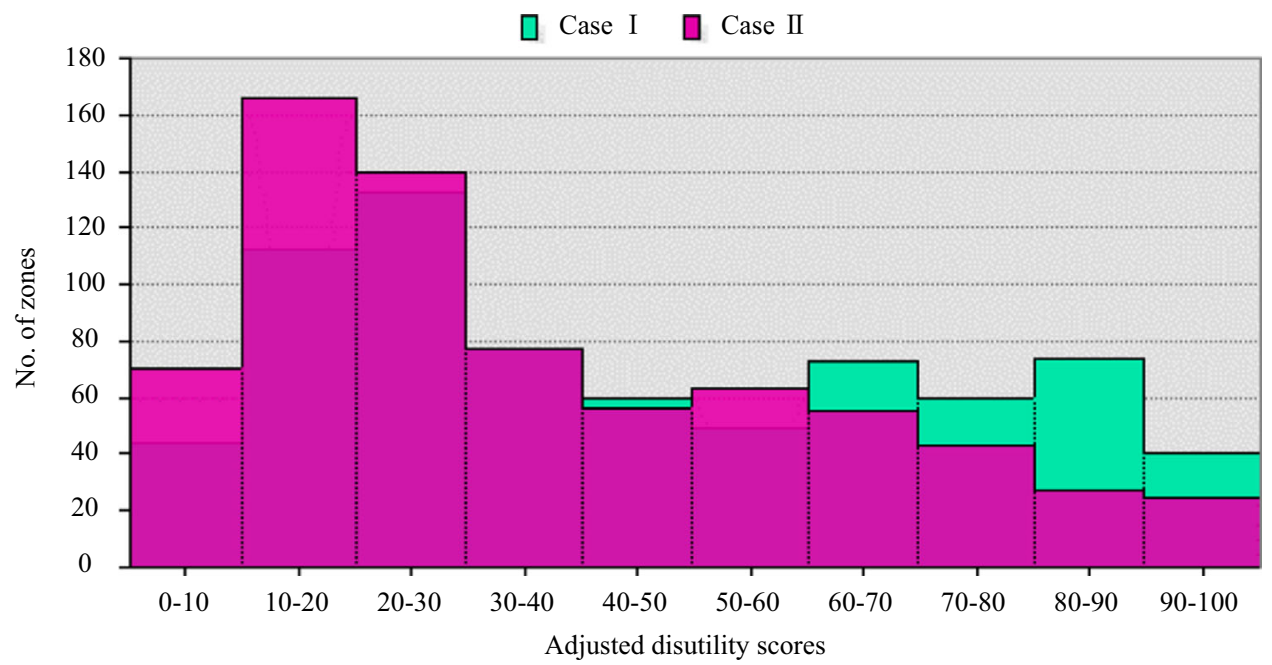

Fig. 8 Comparison of Case I and II histograms 


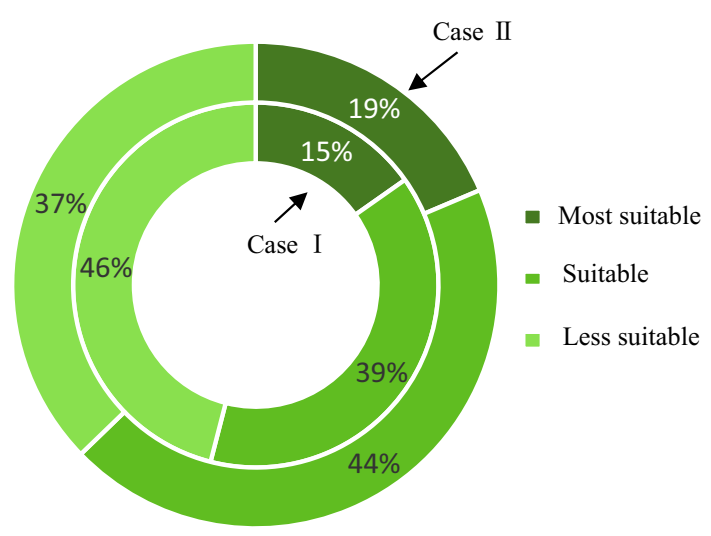

Fig. 9 Distribution of zones' suitability for Case I and II analyses

in the network based on the cost function parameters presented in Table 1.

In this scenario, all segments existing in the network have the same weight factor $\left(\alpha_{j}=1\right)$. All segments were treated equally with no preference either over railways and roads or any specific road category or POI. Spatial analysis was conducted to find the shortest paths between POIs and potential zones. Equations (2) and (3) were used to determine the disutility scores for each potential zone based on the sums of the minimum costs along the shortest paths (estimated based on the cost function assigned to each segment) from each POI to the zone being evaluated. Consequently, Eq. (4) was used to estimate the adjusted
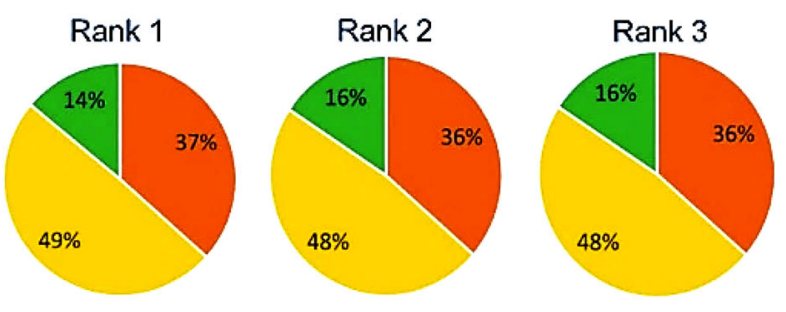

Case I
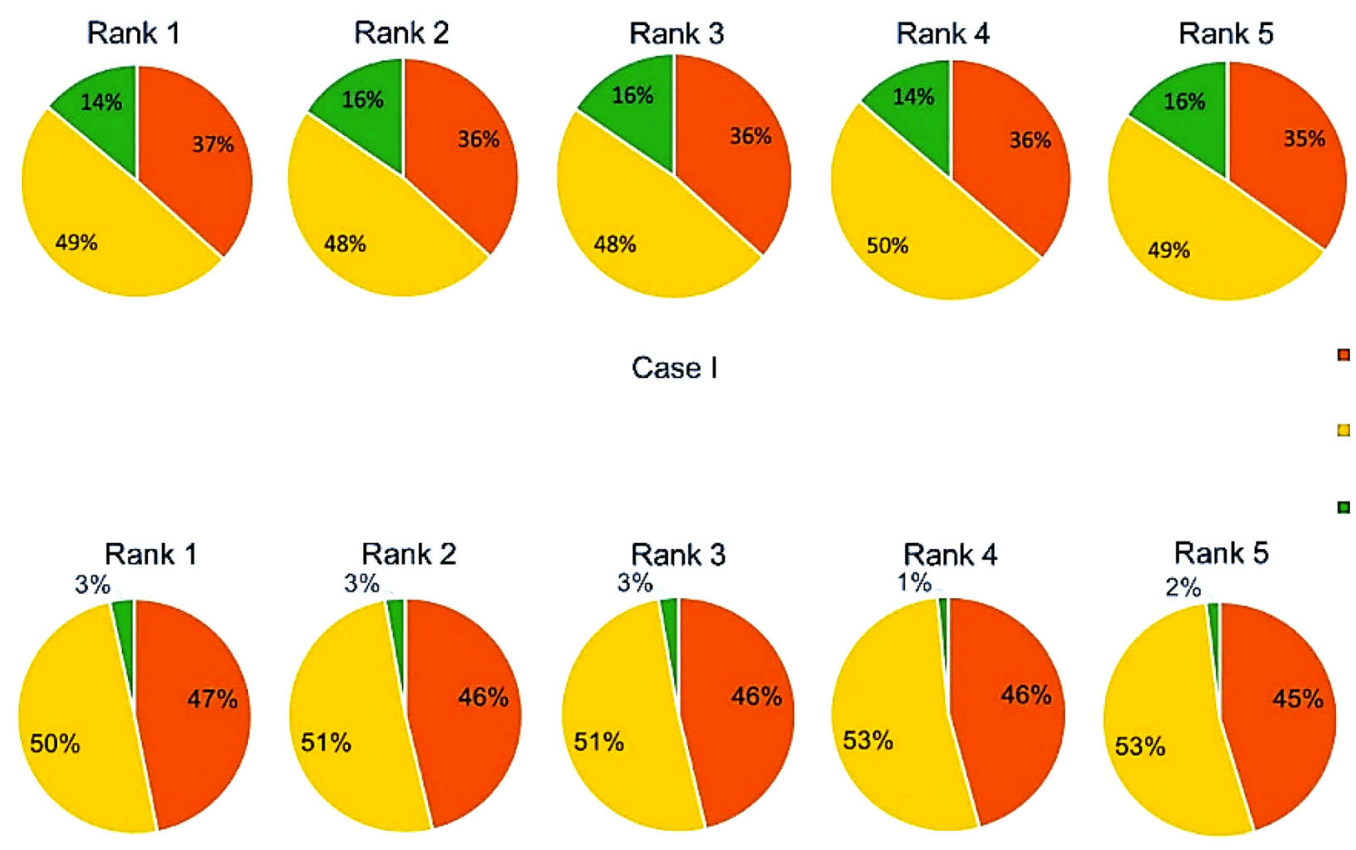

One of the important factors for HAZMAT transportation route planning is segments' structure and functionality, which should satisfy weight and size requirements for HAZMAT transportation. Thus, it is expected that road segments with superior conditions (e.g., geometrical, structural, and surface type) are more preferred. Additionally, railways may be preferred over roads considering additional reliability and safety associated with rail freight transportation. The second case study is a multi-criteria scenario which allows different treatment of network segments based on their hierarchy or functional classification. Consideration of network segment hierarchy has significant impact when estimating the disutility scores for each zone. As indicated in Table 1, the value of the cost function

Railroad

$\square$ Highway (Paved)

a Others

Case II

Fig. 10 Distribution of railway and road segment categories for top five most suitable zones in Case I and II analyses 


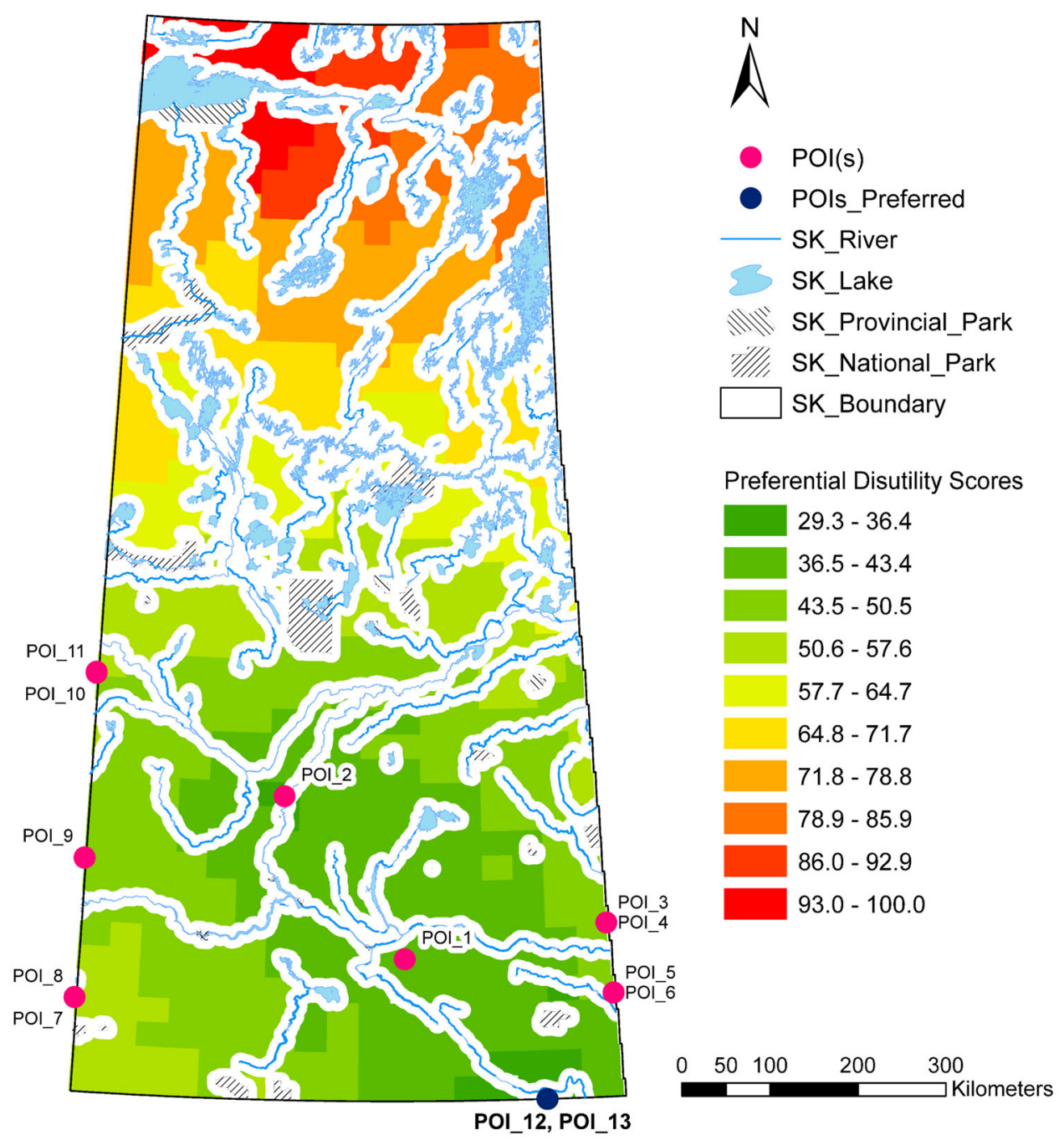

Fig. 11 Case III heat map showing the impact of preferential treatment of POI_12 and POI_13 $(\beta=2)$

assigned to each network segment through Eq. (2) was determined based on the segments' length and a weight factor determined based on the functional category of the segments and their surface type for road segments. To estimate realistic weight factors, a questionnaire survey was conducted to seek experts' opinion on transportation of nuclear materials. The survey is described in more detail in the following section.

\subsubsection{Route planning preference survey for transportation of hazmat}

Experts' opinions were evaluated through a survey regarding transportation of HAZMAT, i.e., nuclear material through different means of transportation. Road segments were classified based on the Federal Highway
Administration (FHWA) highway functional classification system [27]. Fourteen categories of roads and railways (including paved and unpaved roads) were considered in the survey. Experts from different relevant governmental and industrial sectors including highways and infrastructure, regional planning, energy and resources, driver's licensing and vehicle registration, environment, and traffic safety were asked to rank each road category and railways from 1 (most preferred) to 10 (least preferred) keeping in view its suitability for the transportation of nuclear material in terms of potential risks during transportation. In total, 318 invitations were sent, and 40 valid responses were received with a response rate of $12.75 \%$. As indicated in Fig. 3a, the feedback from 40 experts suggested that railways are the most preferred means of transportation for nuclear materials followed by freeways and then paved highways. It can also be observed that the lower hierarchy 


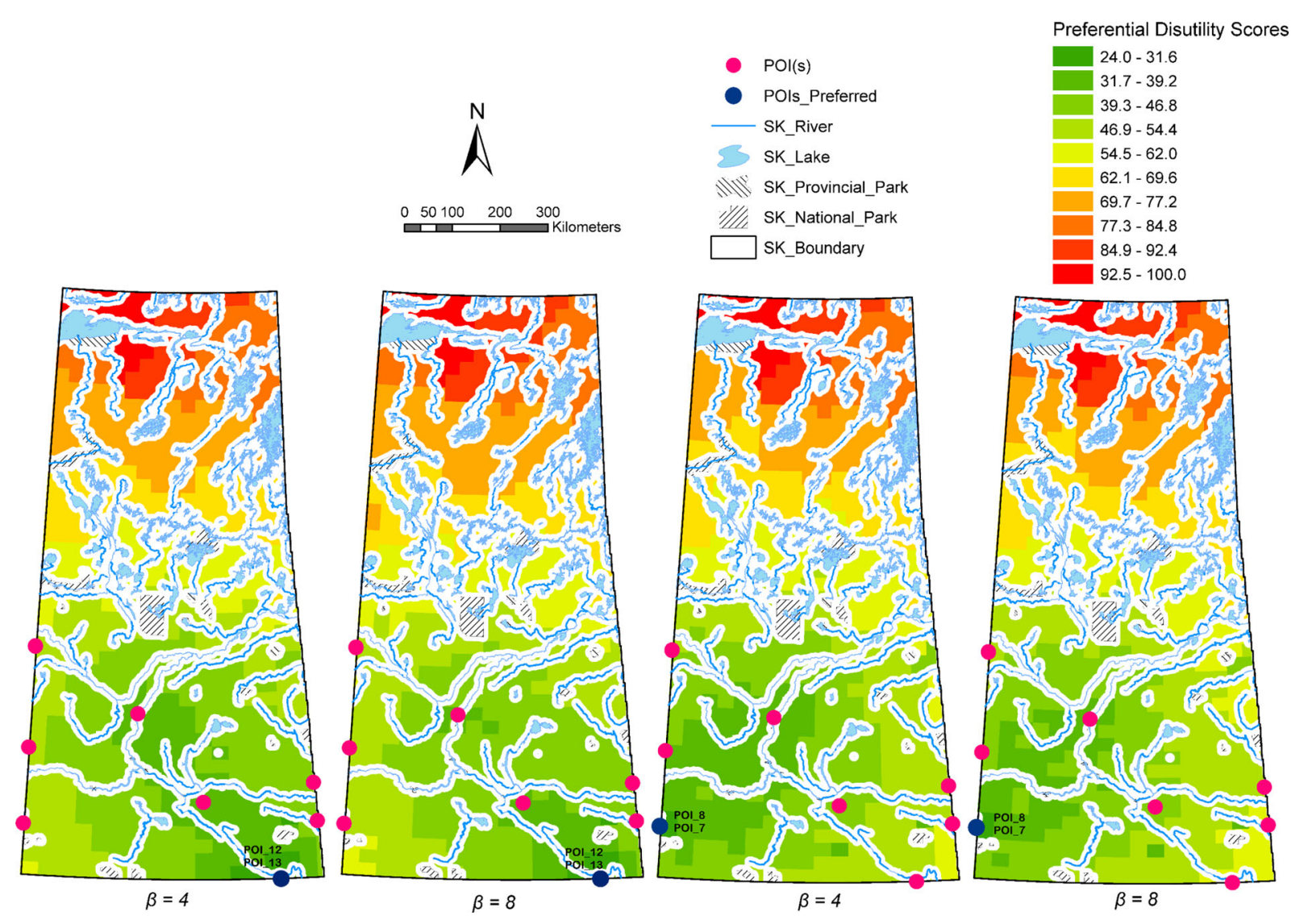

Fig. 12 Case III heat maps showing the impact of different $\beta$ values on preferred POIs

Preferred POls $12 \& 13$

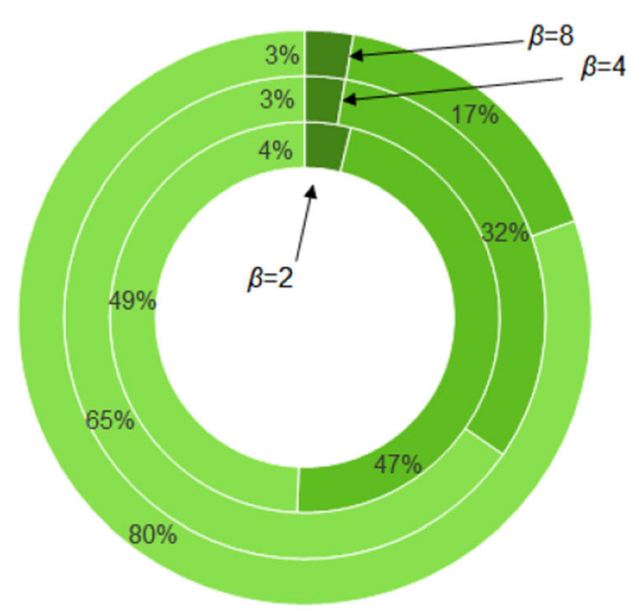

Preferred POls_7 \& 8

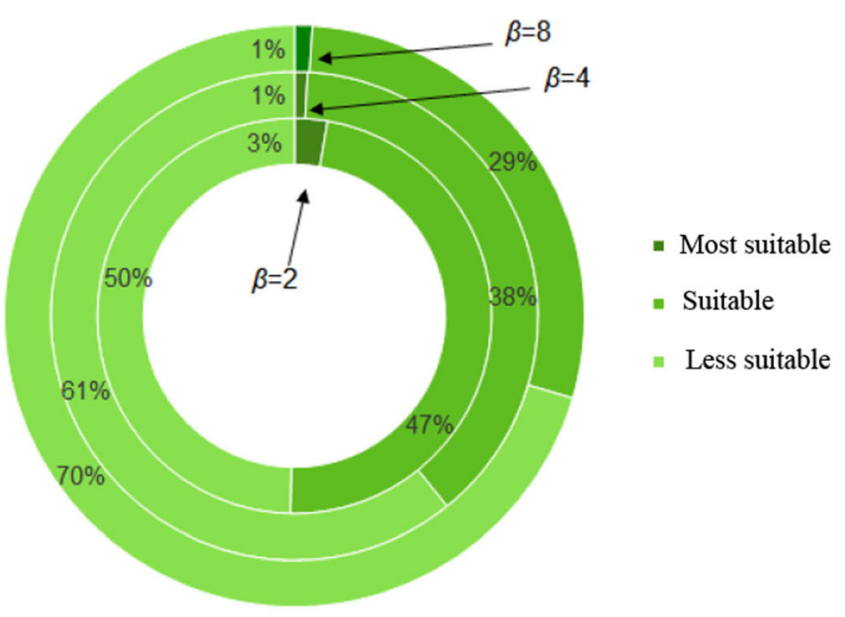

Fig. 13 Distribution of zones' suitability for different $\beta$ values and preferred POIs

roads and the roads with unpaved surface were considered as the least preferred means of transportation for nuclear materials (indicated by higher preferential scores).
It can be seen in Fig. 3a that there is a considerable shift in the cumulative scores given to each road category after paved highway category, indicating that categories in lower 


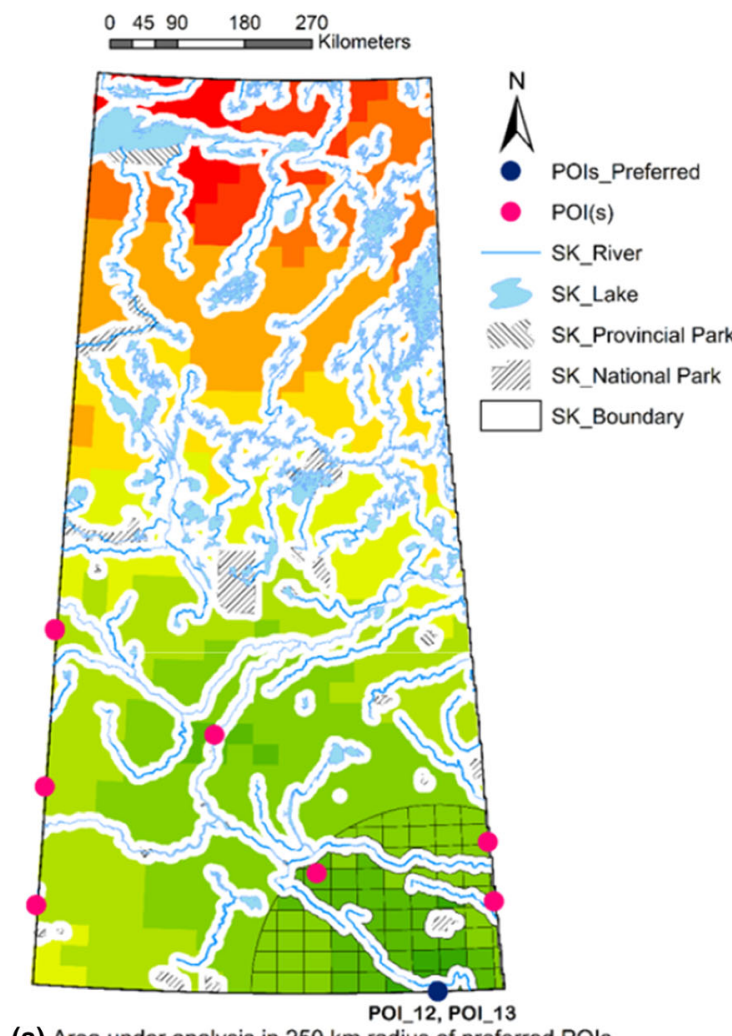

(a) Area under analysis in $250 \mathrm{~km}$ radius of preferred POls

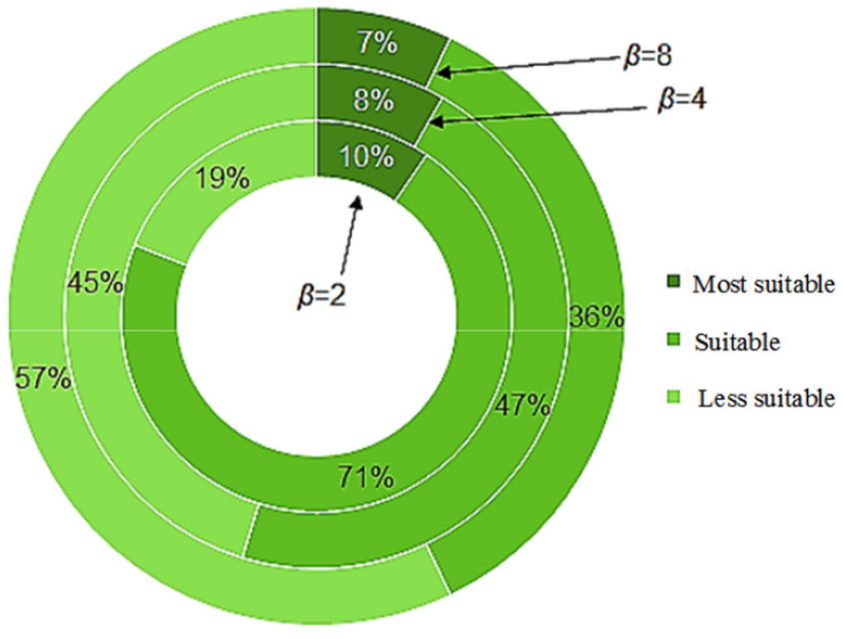

(b) Suitable zones within $250 \mathrm{~km}$ radius of Preferred POls_12 \& 13 with different $\beta$ values

Fig. 14 Comparison of suitable zones in Case III with different $\beta$ values within $250 \mathrm{~km}$ from preferred POIs

hierarchies than paved highways are significantly undesirable for transportation of nuclear materials. Also, road categories in lower hierarchies than collectors seem to be equally undesirable as there is much less difference in their cumulative scores. Further investigation of the survey findings in Fig. $3 \mathrm{~b}$ suggests that $67.5 \%$ of the experts have given rank score of ' 1 ' to railways, while freeways and highways were equally given rank score of ' 1 ' by $25 \%$ of the experts. Similarly, as shown in Fig. 4, lower hierarchy roads and unpaved roads were considered as the least preferred means of transportation for nuclear materials with preference score of ' 10 ' by $45 \%$ to $65 \%$ of the surveyed experts. The survey results suggest that railways, freeways, and paved highways are the most preferred options for transportation of nuclear materials.

The average values of the surveyed preference scores were used to estimate the weight factors for each road category and railways, which were multiplied by the lengths of the segments in the cost function when estimating the disutility scores for potential zones in Case II. Table 2 provides the values used as weight factor $\left(\alpha_{j}\right)$ for each road segment in Eq. (1) in Case II analysis.

\subsection{Case III}

Case III demonstrates the application of the proposed analysis method to prioritize a specific POI(s). In practice, when conducting site selection studies for HAZMAT facilities, a specific POI may be preferred over others. For example, a particular POI which is located on a route that is frequently used to supply HAZMAT, has strategic significance and should be prioritized. The analysis method presented in Case III enables preferential treatment of specific POIs by introducing a priority factor $(\beta>1)$. Ranking of the road and railway segments is based on the preference scores estimated for each category similar to Case II analysis. Thus, appropriate values for the cost function were estimated and assigned to each segment in the network based on the methodology described for Case II analysis.

The shortest path analysis and estimation of ADUS values for each zone are completed in two steps:

1. In the first step, the shortest paths are evaluated between all zones and each preferred POI only. Consequently, for each zone $i, \operatorname{ADUS}_{p i}$, i.e., estimated 


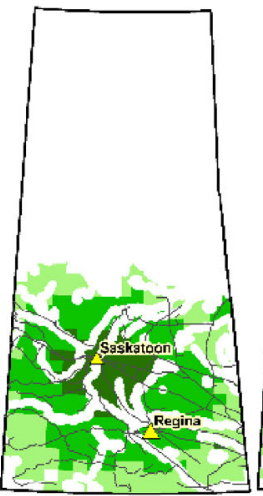

Scenario 1:

(Railway weight factor $=2$ )

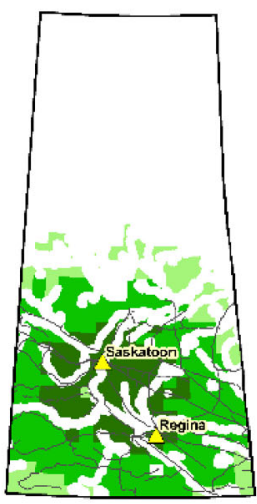

Scenario 6:

(Railway weight factor $=6$ )

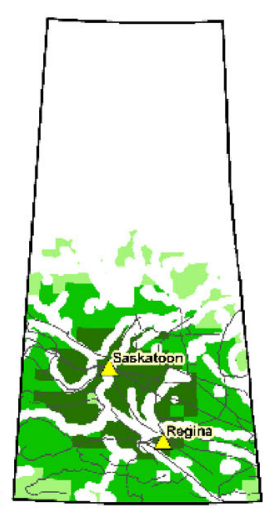

Scenario 7:

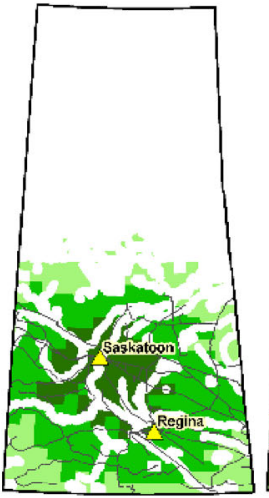

Scenario 3:

(Railway weight factor $=3$ )

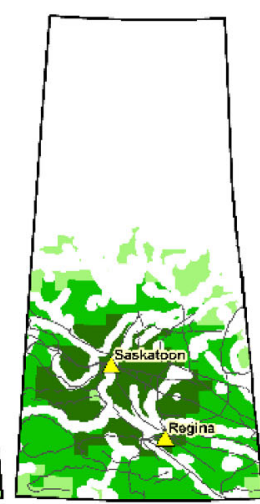

Scenario 8:

(Railway weight factor $=8$ )

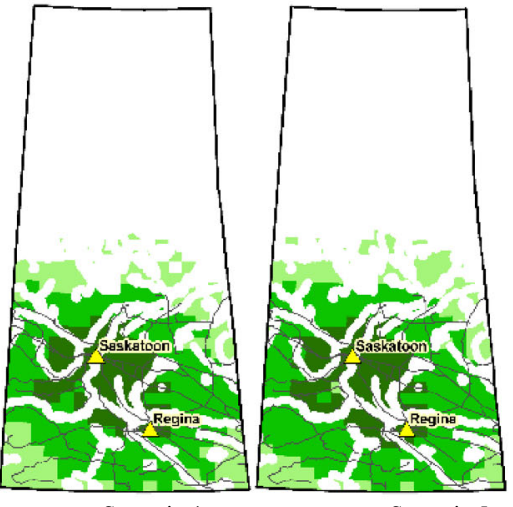

Scenario 5:

Scenario 4:

(Railway weight factor $=4$

(Railway weight factor $=5$ )

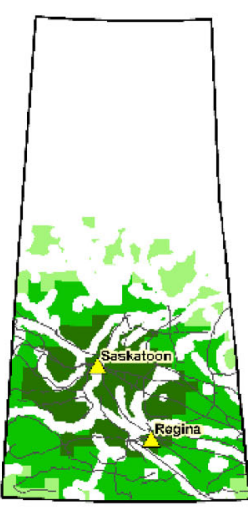

Scenario 9:

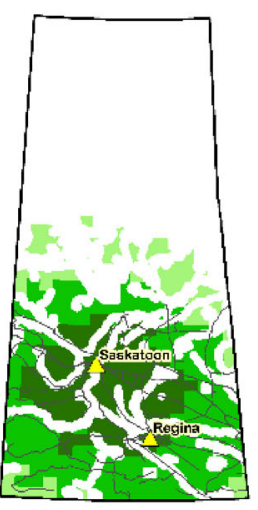

Scenario 9:

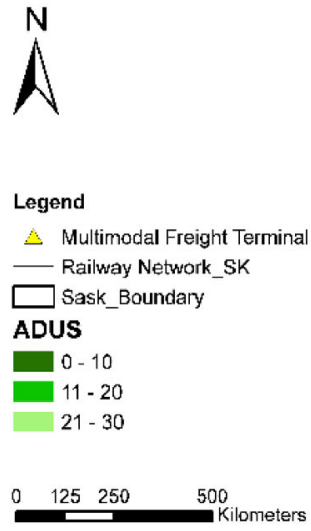

$($ Railway weight factor $=9) \quad($ Railway weight factor $=9)$

Fig. 15 Quantity and spatial distribution of the most suitable, suitable, and less suitable zones considering different railway weight factors

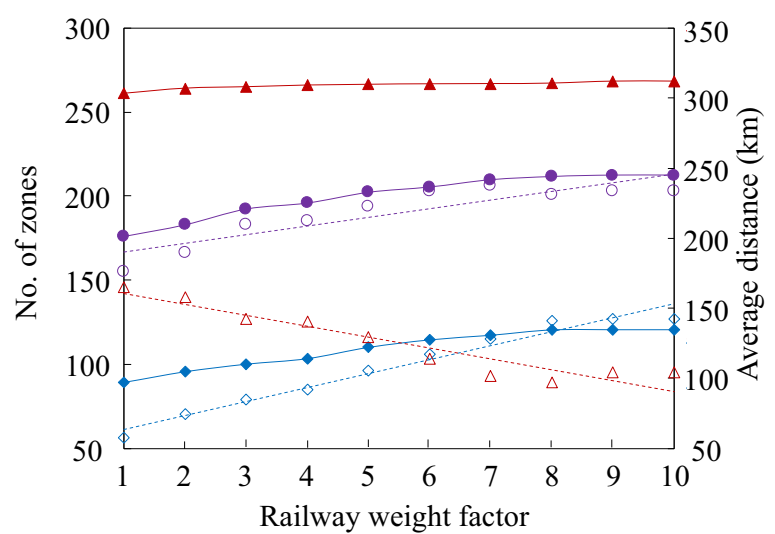

- Avg. distance_most suitable zones

$\diamond$ No. of most suitable zones

Linear (no. of most suitable zones)

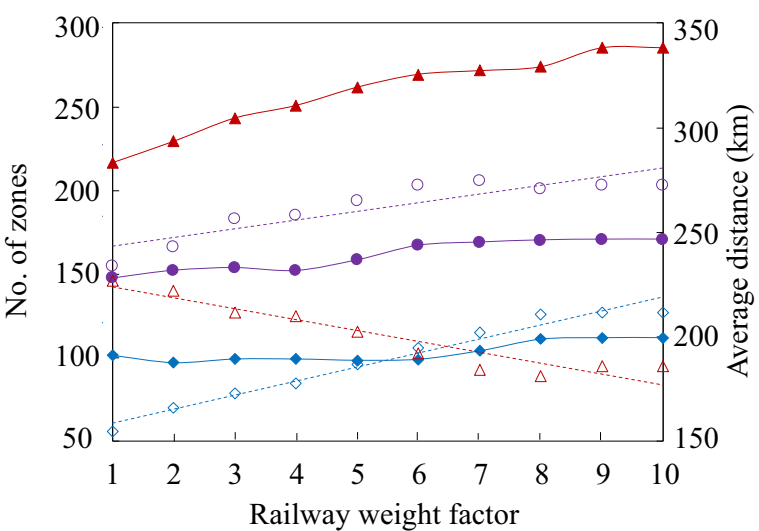

- Avg. distance suitable zones

- No. of suitable zones

Linear (no. of suitable zones)
^ Avg. distance less suitable zones

$\triangle \quad$ No. of less suitable zones

..... Linear (no. of less suitable zones)

(a) Intermodal terminal in saskatoon

(b) Intermodal terminal in regina

Fig. 16 Variation in quantity and average distance of the most suitable, suitable, and less suitable zones from multimodal terminals considering different railway weight factors 
Table 2 Estimated weight factors for different network segment categories

\begin{tabular}{ll}
\hline Road categories & Weight factor $\alpha_{j}$ (mean preference score) \\
\hline Railroad & 2.00 \\
Freeway & 2.88 \\
Highway (paved) & 3.05 \\
Highway (unpaved) & 5.00 \\
Arterial (paved) & 5.25 \\
Arterial (unpaved) & 6.48 \\
Collector (paved) & 6.88 \\
Collector (unpaved) & 7.60 \\
Paved local (paved) & 8.50 \\
Local (unpaved) & 8.85 \\
Alleyway (paved) & 9.15 \\
Alleyway (unpaved) & 9.35 \\
Recreation (paved) & 9.30 \\
Recreation (unpaved) & 9.25 \\
\hline
\end{tabular}

ADUS values considering preferred POI $p$ only, is estimated using Eqs. (2) through (4). If more than one POI is preferred, Step 1 should be repeated for each preferred POI.

2. In the second step, the shortest path analysis is conducted considering the rest of the POIs (excluding preferred POIs). Once the shortest paths from the remaining POIs to potential zones are evaluated, for each zone $i, \operatorname{ADUS}_{r i}$, i.e., estimated ADUS values considering the remaining POIs, is estimated using Eqs. (2) through (4).

Assuming there are $p$ preferred POIs, estimated ADUS values for each zone $i$ in Steps 1 and 2 are combined based on their priority factors $\left(\beta_{p}\right)$ to estimate zone $i$ 's preferential disutility score $\left(\mathrm{PDUS}_{i}\right.$ ) as indicated in Eq. (5). Preferential disutility score is in fact the weighted average of adjusted disutility scores estimated in Steps 1 and 2 based on the priority factors assigned. POIs with greater priority factors have more influence on each zone's preferential disutility score:

$\operatorname{PDUS}_{i}=\frac{\sum_{p=1}^{p}\left(\beta_{p} \times \operatorname{ADUS}_{p i}\right)+\operatorname{ADUS}_{r i}}{1+\sum_{p=1}^{p} \beta_{p}}$.

Finally, PDUS values are used for evaluating the suitability of zones as potential sites (instead of ADUS values in Cases I and II).

\section{Sensitivity analysis}

The case studies presented in this research pertain to the province of Saskatchewan. Further, the weight factors used in Case II and Case III analyses were based on a survey conducted in Saskatchewan. However, preference scores and resulting weight factors may vary if the survey was conducted in a different jurisdiction considering the sample size, availability of road and railway categories, local regulations, and experts' opinion. A sensitivity analysis was conducted to demonstrate the impact of variations in weight factors on spatial distribution of zones considering their suitability as potential HAZMAT facility site. For demonstration purpose and to control for the impact of interactions, only variation in railway weight factor was analyzed considering Case II analysis. Ten scenarios were defined by varying railway weight factor from 1 (most preferred) to 10 (least preferred) while keeping the weight factors of all other road categories unchanged. As discussed in Sect. 4.1, considering the distribution of ADUS values, ten equal intervals (bins) were considered to classify zones based on their ADUS values. For simplicity, the zones with ADUS values within the first three bins were assumed to represent the most suitable, suitable, and less suitable zones, respectively. The remaining zones with greater ADUS values were considered unsuitable. The quantity and spatial distribution of the most suitable $(0<$ ADUS $\leq 10)$, suitable $(10<$ ADUS $\leq 20)$, and less suitable $(20<$ ADUS $\leq 30)$ zones were evaluated and analyzed in each scenario, which will be discussed in the proceeding section.

\section{Results and discussion}

The results of Case I analysis are presented in Fig. 5, which show the spatial distribution of potential zones considering their suitability for a HAZMAT facility site. Dark green areas indicate the most suitable zones, while dark red regions represent unsuitable zones. Figure 6 represents the distribution of ADUS values for all zones in Case I analysis. The histogram in Fig. 6 demonstrates a bimodal distribution. The zones in northern Saskatchewan are very far from all POIs and relatively inaccessible. Thus, their ADUS values are significantly large. On the other hand, zones in southern Saskatchewan are very accessible due to a dense road and railway network, which resulted in much smaller ADUS values for these zones. The analysis results indicate that the areas around the cities of Regina and Saskatoon are more suitable for the HAZMAT facility site if all road and railway segments are treated equally with no preference toward any specific POIs.

In Case II analysis, after assigning appropriate cost function values to each segment in the network, the shortest path analysis was conducted to find the routes with minimum cost between each potential zone and POIs. Consequently, Eqs. (2) and (3) were used to estimate DUS and ADUS values for each potential zone. The heat map 
presenting the suitability of the zones as the HAZMAT facility site based on the criteria considered in Case II is presented in Fig. 7. It can be observed that the majority of optimal zones are still located in southern Saskatchewan. However, by comparing the results of Case I (Fig. 5) and Case II (Fig. 7) analyses, color shifts indicating the changes in the location of optimal zones can be detected. Unlike the results presented for Case I analysis, the optimal zones in Case II are shifted toward POI_2 located in Saskatoon, which is due to the existence of a multimodal freight terminal with comparatively better connectivity to the road network. This is because the railways were given the highest priority (least weight factor) by the experts for transportation of nuclear materials (Table 2). Thus, the optimal zones concentrate in the vicinity of multimodal freight terminals. It should be noted that although there is another multimodal freight terminal near Regina, the zones around the multimodal freight terminal in Saskatoon are prioritized due to better connectivity and accessibility from all POIs. Figure 8 compares the distribution of estimated zonal ADUS values in Case I and Case II analyses. Clear shifts are identified in the distribution of ADUS across different zones as a result of assigning different weight factors to various segments in the network. The chart in Fig. 9 compares the variation in the number of the most suitable, suitable, and less suitable zones (as defined in Sect. 5). Zones were evaluated based on their suitability as a potential site for the HAZMAT facility considering Case I and Case II analyses. It can be observed that the number of the 'most suitable' and 'suitable' zones has increased from $15 \%$ to $19 \%$, and $39 \%$ to $44 \%$, respectively. However, the number of 'less suitable' zones has decreased proportionally. The variations are due to applying different weight factors to each segment considering its functional category. The changes in the number of zones show that the disutility of the zones is affected when different network segments are given certain preferences. To further analyze the effects of incorporating weight factors to prioritize network segments based on their functional category, the distribution of network segments constituting the least cost routes between POIs and selected zones was analyzed. Figure 10 compares the distribution of network segment categories in the least cost routes between all POIs and top five most suitable zones (with lowest disutility scores) as identified by the analysis in Case I and Case II. It can be observed that the share of paved highways and railways in composition of the least cost routes across all top five zones has increased significantly in Case II analysis as compared to Case I, which was expected as paved highways and railways were given the highest priorities for HAZMAT transportation in Case II analysis. Furthermore, the share of other road categories has significantly reduced (from $14 \%-16 \%$ to $1 \%-3 \%$ ), which reflects less preference toward the remaining road categories in the network for HAZMAT transportation. It should be noted that the share of freeways was negligible because the freeway network in Saskatchewan is very limited.

Case III analysis enhances the study conducted in Case II as it allows assigning priority factors $(\beta)$ to preferred POIs. For demonstration purpose, the POIs defined along the southern border of Saskatchewan with the USA (POIs 12 and 13) were considered as preferred POIs with priority factor $\beta=2$. The heat map in Fig. 11 compares the suitability of zones as potential sites for the HAZMAT facility considering preferences toward network segment categories and preferential treatment of selected POIs. The impact of prioritizing POIs 12 and 13 can be confirmed by comparing Fig. 11 with Figs. 5 and 7 as most optimal zones are shifted further south toward preferred POIs. Figure 12 compares different scenarios in which POIs 7 and 8 along Alberta border and POIs 12 and 13 along the US border are preferred by applying priority factors $\beta=4$ and $\beta=8$. In each scenario, it is shown that when a greater priority factor is applied to the same POIs, there is a reduction in the number of optimal zones in areas around the less preferred remaining POIs, while optimal zones near highly preferred POIs are maintained or increased. In Case III analysis, ten equal intervals (bins) were considered to classify zones based on their PDUS values. The zones with PDUS values within the first three bins were assumed to represent the most suitable, suitable, and less suitable zones, respectively. Figure 13 demonstrates the variations in the number of zones with respect to their suitability as potential sites for the HAZMAT facility considering the scenarios in Case III analysis. It can be seen that the number of 'most suitable' and 'suitable zones' decreases in each scenario as a result of applying greater $\beta$ values while the number of less suitable zones increases proportionally, which indicates the impact of setting stronger preference toward specific POIs. In other words, as the value of $\beta$ increases, only the zones with good access which are also closer to preferred POIs will be qualified as 'most suitable' or 'suitable.' To further investigate the impact of assigning different $\beta$ values for specific POIs, Fig. 14 compares the distribution of the number of zones based on their suitability within $250 \mathrm{~km}$ from the preferred POIs at the US border. Figure $14 \mathrm{~b}$ shows that as the value of $\beta$ increases, the zones located farther from preferred POIs will be identified as 'less suitable.' Therefore, the number of 'most suitable' and 'suitable' zones within $250 \mathrm{~km}$ from preferred POIs decreases significantly, which implies that only accessible zones which are closer to preferred POIs will be identified as 'most suitable' and 'suitable.' It should be noted that the values adopted for $\beta$ are merely for demonstration purpose. In practice, $\beta$ values should be determined based on the perceived priority of each POI.

As discussed in Sect. 5, a sensitivity analysis was conducted to investigate the changes in the frequency and spatial 
distribution of zones with respect to their suitability as the HAZAMAT facility site considering the variations in weight factors assigned to network segment categories. Ten scenarios were evaluated by changing the weight factor of railways from 1 to 10 while keeping the weight factors of other network segments (i.e., road categories) unchanged. Figure 15 shows the results of the analysis for each scenario with respect to spatial distribution of the most suitable, suitable, and less suitable zones as defined in Sect. 5. In the first scenario where the railways are set as the most preferred network segment for HAZMAT transportation (weight factor $=1$ ), the most suitable zones are concentrated around the multimodal terminal in Saskatoon, which is due to its better connectivity with rail and road network and accessibility from all POIs. By increasing the railway weight factor, the most suitable and suitable zones spread out toward the multimodal terminal in Regina, which also provides good connectivity to railway and road network while being accessible from all POIs. The results indicate that as the preference toward railways as HAZMAT transportation route decreases further (indicated by greater weight factors), the quantity of the most suitable and suitable zones shows an increasing trend while their spatial distribution spreads away from multimodal terminals in Saskatoon and Regina. Figure 16 demonstrates the observed trends quantitatively. The average distance from the most suitable and suitable zones to multimodal terminals in Saskatoon and Regina shows an increasing trend as the preference toward railways as HAZMAT transportation route decreases. As the preference toward railways decreases, other competing network segment categories such as paved highways become a more viable option for HAZMAT transportation. Thus, the most suitable and suitable zones spread away from multimodal terminals to areas with better access to paved highways which are mainly in southern Saskatchewan. Accordingly, the quantity of less suitable zones shows a decreasing trend indicating that zones previously labeled as 'less suitable' are re-identified as 'suitable' or 'most suitable' as a result of reduced preference for HAZMAT transportation through railways. The zones in northern Saskatchewan are classified as unsuitable in all scenarios evaluated due to their remoteness and limited access to railway and road network.

\section{Conclusions}

A methodology was proposed to identify and rank the optimum sites for HAZMAT facilities considering accessibility and transportation preferences. The proposed method considers a multimodal transportation network including roads and railways and incorporates HAZMAT route planning into HAZMAT facility siting considering experts' opinions to prioritize network segment (i.e., railway and road) categories for HAZMAT transportation.

The area of interest is divided into smaller zones representing potential sites for the HAZMAT facility. A set of desired POIs are identified along major highways and railways in the area of interest indicating essential origin and destination points, which should be accessible from the HAZMAT facility site. A cost minimization algorithm is applied to evaluate the shortest paths between all POIs and each zone in the network, which is used to establish a disutility score for zones. The cost function assigned to network segments allows incorporating transportation preferences into HAZMAT route planning based on functional classification of network segments. Transportation preferences are considered by assigning specific weight factors to each network segment category based on their functional classification and experts' opinion. Zone disutility scores are used for ranking the zones in terms of their suitability as the HAZMAT facility site. Applications of the proposed methodology were demonstrated based on several case studies using the Canadian province of Saskatchewan as an example. The case studies presented different aspects and applications of the proposed analysis method including preferential treatment of specific network segment categories and POIs. Finally, a sensitivity analysis was conducted to evaluate the changes in the frequency and spatial distribution of zones with respect to their suitability as the HAZAMAT facility site considering the variations in weight factors assigned to network segment categories.

The proposed methodology only considers accessibility and transportation preferences to identify optimal locations for HAZMAT facilities. However, to generalize the methodology, other factors such as transportation risks (including the risks to humans and environment), availability of emergency response centers, and road geometry and loadbearing capacity should be considered as additional decision criteria. Yet, as each decision criterion may have a different unit, the methodology should allow incorporating inhomogeneous decision criteria into the analysis, which will be addressed in future extensions of this research. Furthermore, to improve the efficiency of the proposed analysis method, data reduction methods could be considered to reduce the intensity of spatial data analysis subject to required level of accuracy and availability of computational resources.

Acknowledgements This research was supported by Sylvia Fedoruk Canadian Centre for Nuclear Innovation.

Open Access This article is distributed under the terms of the Creative Commons Attribution 4.0 International License (http:// creativecommons.org/licenses/by/4.0/), which permits unrestricted use, distribution, and reproduction in any medium, provided you give appropriate credit to the original author(s) and the source, provide a link to the Creative Commons license, and indicate if changes were made. 


\section{References}

1. Transport Canada (2018) Transportation of Dangerous Goods Regulations. Ministry of Justice, Canada. http://laws-lois.justice. gc.ca. Accessed 18 Feb 2019

2. Transport Canada (2017) Transportation of Dangerous Goods Act, 1992. Ministry of Justice, Canada. http://laws-lois.justice.gc. ca. Accessed 18 Feb 2019

3. IAEA Nuclear Security Series No. 26-G (2015) Security of Nuclear Material in Transport. International Atomic Energy Agency. https://www-pub.iaea.org/MTCD/Publications/PDF/ Pub1686_web.pdf. Accessed 18 Feb 2019

4. Dilgir R, Zein SR, Popoff A (2005) Dangerous goods route selection criteria. TAC/ATC 2005-2005 Annual Conference and Exhibition of the Transportation Association of Canada: Transportation-Investing in Our Future conf.tac-atc.ca/english/resourcecentre/readingroom/conference/conf2005/.../dilgir.pdf

5. Shaver DK, Kaiser M (1998) Criteria for highway routing of hazardous materials. Transportation Research Board, Washington

6. Deng X, Lu X, Chan FTS, Sadiq R, Mahadevan S, Deng Y (2015) D-CFPR: D numbers extended consistent fuzzy preference relations. Knowl-Based Syst 73:61-68

7. Wang N, Huang X, Wei D (2016) Route selection for dangerous goods based on D numbers. In: Proceedings of the 28th Chinese Control and Decision Conference, CCDC 2016, vol 1, pp 6651-6656

8. Baja S, Chapman DM, Dragovich D (2007) Spatial based compromise programming for multiple criteria decision making in land use planning. Environ Model Assess 12(3):171-184

9. Li R, Leung Y (2011) Multi-objective route planning for dangerous goods using compromise programming. J Geogr Syst 13(3):249-271

10. Ma C (2018) Network optimization design of Hazmat based on multi-objective genetic algorithm under the uncertain environment. Int J Bio-Inspir Comput 12(4):236-244

11. Ma C, Hao W, Pan F, Xiang W (2018) Road screening and distribution route multi-objective robust optimization for hazardous materials based on neural network and genetic algorithm. PLoS ONE 13(6):e0198931. https://doi.org/10.1371/journal.pone.019 8931

12. Erkut E, Ingolfsson A (2000) Hazardous materials route planning. Transp Sci 34(2):165-179

13. Rocchi S, Law V, Stanker G (2009) Prince George Dangerous Goods Routes-a comprehensive evaluation method. The City of Prince George
14. Sen A, Onden I, Gokgoz T, Sen C (2011) A GIS approach to fire station location selection. In: GI4DM 2011 geoinformation for disaster management conference, pp 1-6

15. Rikalovic A, Cosic I, Lazarevic D (2014) GIS based multi-criteria analysis for industrial site selection. Proc Eng 69:1054-1063

16. Yesilnacar MI, Suzen ML, Kaya BS, Doyuran V (2012) Municipal solid waste landfill site selection for the city of SanliurfaTurkey: an example using MCDA integrated with GIS. Int J Digit Earth 5(2):147-164

17. Kazemi M, Kunt AI, Larijani RJ (2013) Optimization model for fire station location based on GIS and python: a case study in North Cyprus. Appl Mech Mater 330:1059-1064

18. Erden T, Coşkun MZ (2010) Multi-criteria site selection for fire services: the interaction with analytic hierarchy process and geographic information systems. Nat Hazards Earth Syst Sci 10(10):2127-2134

19. Yang L, Jones BF, Yang SH (2007) A fuzzy multi-objective programming for optimization of fire station locations through genetic algorithms. Eur J Oper Res 181(2):903-915

20. Liu N, Huang B, Chandramouli M (2006) Optimal siting of fire stations using GIS and ANT algorithm. J Comput Civ Eng 20(5): 361-369

21. Omitaomu OA, Liu C, Cetiner MS, et al. (2013) Identifying potential areas for siting interim nuclear waste facilities using map algebra and optimization approaches. In: Proceedings of the 2013 industrial and systems engineering research conference

22. Omitaomu OA, Blevins BR, Jochem WC, et al. (2012) Adapting a GIS-based multicriteria decision analysis approach for evaluating new power generating sites. Appl Energy 96:292-301

23. Yesilnacar MI, Cetin H (2005) Site selection for hazardous wastes: a case study from the GAP area, Turkey. Eng Geol 81(2005):371-388

24. Natural Resource Canada (2011) National Topographic System (NTS). Government of Canada. http://publications.gc.ca/site/eng/ 383089/publication.html. Accessed 26 Nov 2018

25. Natural Resources Canada (2017) National Road Network-NRNGeoBase Series. Government of Canada. https://open.canada.ca. Accessed 30 June 2017

26. Natural Resources Canada (2018) National Railway NetworkNRWN-GeoBase Series. Government of Canada. https://open. canada.ca. Accessed 30 May 2018

27. Federal Highway Administration (2013) Highway Functional Classification Concepts, Criteria and Procedures. FHWA, US Department of Transportation. https://www.fhwa.dot.gov/planning/ processes/statewide/related/highway_functional_classifications/ fcauab.pdf. Accessed 6 May 2018 